Cuadernos de Pensamiento $\mathrm{N}^{\mathrm{o}} 32$

Número monográfico sobre Karol Wojtyla/san Juan Pablo II en el centenario de su nacimiento. Volumen 1.

Año: 2019

DOI: https://doi.org/10.51743/cpe.54

\title{
La originalidad del método filosófico de Karol Wojtyła en Persona y acción
}

\section{The originality of the philosophical method of Karol Wojtyła in The Acting Person}

PEDRo García CASAS

Pontificia Universidad Gregoriana

\begin{abstract}
RESUMEN: El objeto de este artículo consiste en adentrarse en la especificidad del método filosófico de Karol Wojtyła expuesto en su gran obra filosófica Persona y acción. Para ello, iremos explicando y detallando los aspectos más sobresalientes de dicho método para desde ahí poder entender el modo de filosofar wojtyliano. Veremos las influencias del tomismo, de la fenomenología y del personalismo en la elaboración de dicho método, pero dejando claro al mismo tiempo cómo Wojtyła no queda constreñido al método, sino que se vale de este como instrumento para llegar al núcleo de la persona, objeto principal del pensamiento de Wojtyła. En ente sentido, veremos cómo la experiencia, no en sentido fenoménico, será la vía que permitirá elaborar una antropología adecuada que tenga en cuenta no sólo la objetividad sino la misma subjetividad de cada persona, de toda persona.
\end{abstract}

PALABRAS CLAVE: acción; experiencia; inducción; reducción; persona

ABSTRACT: The object of this article is to explore the specificity of Karol Wojtyla's philosophical method exposed in his masterpiece The acting person. In order to do this, we will explain the most outstanding aspects of this method in order to under- 
stand the Wojtylian way of philosophizing. We will see the influences of Thomism, Phenomenology and Personalism in the development of this method, but making it clear at the same time how Wojtyła is not constrained to the method, but uses it as an instrument to reach the center of the human person. Experience, not in a phenomenal sense, will be the way that will allow us to elaborate an adequate anthropology that takes into account not only the objectivity but also the subjectivity of each person, of every person.

KEYWORDS: action; experience; induction; reduction; person

\section{INTRODUCCIÓN}

E ste artículo consiste en la exposición del método filosófico del que se vale Karol Wojtyła para integrar la corriente objetivista acerca del hombre (centrada en la metafísica fundamentalmente) y la subjetivista (que tiene en cuenta la subjetividad, la consciencia, el yo, etc.). De esta manera, estableciendo un método totalmente original y propio Wojtyła elabora una antropología que hace justicia a la realidad personal y desde la cual luego podrá pasar a una meta-ética. No olvidemos que Wojtyła es profesor de ética, y si en esta obra se centra en una perspectiva antropológica lo hace como medio para fundamentar la ética, dándole un soporte sólido y llegar así a una meta-ética, que va más allá de los preceptos éticos.

Este estudio lo dividiremos en dos partes, en la primera estudiaremos el impacto de la obra Persona y acción, de la cual surgió una serie de debates que es necesario al menos referenciar para entender la trascendencia del autor y de su obra. Posteriormente, pasaremos a la exposición detallada y pormenorizada del método filosófico wojtyliano.

Tras el estudio de Kant y su concepción del mundo empírico y el estudio de la fenomenología de Scheler, veremos la importancia capital que otorga Wojtyła a la experiencia como fuente de conocimiento, especialmente conocimiento sobre el mismo hombre y su acción.

El conocimiento del hombre queda fundado sobre la misma experiencia (no en el sentido empírico como lo entiende Hume) que el mismo hombre 
tiene de sí mismo y del hombre en general. Asimismo, el hombre se revela en la acción la cual puede perfeccionar al hombre o no. De aquí que toda acción del hombre llevada a cabo desde la libertad tenga un componente moral.

Finalmente abordaremos dos elementos fundamentales en el método wojtyliano a la hora de tomar la experiencia como fuente de conocimiento: la inducción y la reducción. Tras explicar en qué consisten veremos cómo tanto la una como la otra son, al mismo tiempo, inmanentes y trascendentes a la vivencia experimental.

\section{PERSONA Y ACCIÓN ${ }^{1}$}

La originalidad de Persona y acción estriba en ser la obra donde Wojtyła pretende refundar la antropología realista a la luz del pensamiento moderno, especialmente a través de todo lo que ha supuesto en su trayectoria intelectual el acercamiento a la Fenomenología (a través de Max Scheler) y al Personalismo. Wojtyła comprende que no es posible elaborar una antropología moderna partiendo únicamente de los conceptos aristotélico-tomistas, sino que debe integrar en la antropología (aristotélico-tomista: cimentación desde la que parte) la subjetividad, la autoconciencia, la autorreferencialidad, el yo, etc., ${ }^{2}$ lo cual no es posible hacerlo desde un planteamiento meramente escolástico.

\footnotetext{
${ }^{1}$ No resulta fácil saber con exactitud cuándo tuvo lugar la redacción de esta obra, Wojtyła comenta que "mientras escribía este estudio, participaba en los trabajos del Concilio Vaticano II, y esto se convirtió también en un impulso para meditar en torno a la persona" (K. WojtyŁa, Persona y acción, Palabra, Madrid 2014, 79). Tampoco se puede precisar con exactitud la discusión de la obra en los círculos filosóficos polacos: "Tadeusz Styczen narra, por ejemplo, que Wojtyla conoce a Roman Ingarden en 1956. E insiste en que a partir de esa fecha los jueves por las tardes tenian lugar conversaciones filosóficas en el palacio arzobispal de Cracovia en las que el propio Ingarden eventualmente expuso a los asistentes su libro Sobre la responsabilidad, y en las que Wojtyla ya portaba un manuscrito intitulado Osoba i czyn (R. GuERrA, Volver a la persona, Caparrós, Madrid 2002, 197).

${ }^{2}$ Wojtyła tiene en mente una visión netamente pastoral, lleva consigo todos los interrogantes que los jóvenes a su cargo le planteaban sobre el amor, la sexualidad, el matrimonio, etc., y a los que desde una visión puramente objetivista es incapaz de responder a estos interrogan-
} 
Al mismo tiempo, Wojtyła es consciente de que asumir sin más los presupuestos modernos sin una base realista-metafísica fácilmente puede conducir al idealismo, de lo cual tuvo sobrada experiencia con los diferentes totalitarismos en su propia Polonia natal. La respuesta a este complejo problema fue original y arriesgada, ya que Wojtyła realiza una completa reconstrucción de los conceptos antropológicos a partir de la filosofía tomista añadiéndole toda la parte subjetiva e irreductible del hombre desde una perspectiva personalista.

En este sentido, para Wojtyła la antropología se construye desde el sujeto, no desde los principios metafísicos, pero como expresa Burgos a este respecto "al mismo tiempo, la acción de la persona debe entenderse como real, consistente y densa [...] es la acción de un yo con consistencia ontológica" ${ }^{3}$.

Antes de continuar con el objeto del estudio, conviene señalar que hay muchas teorías e interpretaciones e incluso controversias sobre el pensamiento wojtyliano en Persona y acción ${ }^{4}$ y sobre Karol Wojtyła como filósofo. Digamos que no ha habido un acuerdo homogéneo debido a la originalidad que supone el método filosófico de Wojtyła tomando de una u otra corriente e incluso queriendo integrar varias. Esto ha llevado a que se le catalogue como tomista, fenomenólogo y/o personalista.

Aquellos que sostienen que Wojtyła es tomista apoyándose constantemente en Tomás de Aquino ven la influencia fenomenológica en su pensamiento como algo superficial que contribuye simplemente a un enriquecimiento temático. En esta línea encontramos por ejemplo a Lobato que afirma que "Wojtyła es un tomista de fondo, aunque sea a veces un crítico de los modos de presentarse el tomismo contemporáneo".

tes. En cambio, descubre en la fenomenología un instrumento adecuado para llegar a esas experiencias del hombre, un instrumento adecuado pero insuficiente; por eso nunca abandonará ni menospreciará la metafísica.

${ }^{3}$ Burgos, J.M., Para comprender a Karol Wojtyla, BAC, Madrid 2014, 57.

${ }^{4}$ GUERRA, R, Volver a la persona, o.c., 261-312.

5 LobAto, A, "La persona en el pensamiento de Karol Wojtyła", in: Angelicum, n. 56 (1979) 208-209. Cf. también M. RUMAYOR, "Subjetividad sin subjetivismo”: ¿La antropología filosófica de Karol Wojtyła sin la metafísica de Tomás de Aquino?”, in: Tópicos, n. 35 (2008) 57-91. 
Además, en este grupo encontramos con matices distintos las interpretaciones de: Miecyslaw Albert Krapiec, Georges Kalinowski, Andrew N. Woznicki, Jerzy W. Galkowski, Kenneth Schmitz y Jarolslaw Kupczak.

Otro grupo importante de filósofos han considerado a Wojtyła como $\mathrm{fe}$ nomenólogo-descriptivo, para quien la influencia de la fenomenología en su pensamiento habría sido tan importante que le habría alejado del tomismo. Esta idea es sostenida por M. T. Tymieniecka, Wierbicki o J. L. Marion ${ }^{6}$.

Desde la fenomenología realista han considerado a Wojtyła como un fenomenólogo realista: Lévinas, Hans Köchler, J. L. Marion ${ }^{7}$, Rocco Buttiglione, Josef Seifert, Juan Miguel Palacios, Józef Tischner, Massimo Serreti, John H. SI, Robert F. Harvanek SI y Constantino Esposito.

Finalmente, la última línea de pensamiento sostiene que "el Wojtyła maduro de Persona y acción no podría adscribirse ni a la corriente tomista ni a la fenomenológica porque le separan de ambas una distancia excesiva. $\mathrm{Su}$ pensamiento se debería considerar como una antropología original de corte personalista (Buttiglione, Burgos, Merecki, Franquet, Guerra)"

A nuestro juicio nos parece que el debate fue (ya que ha dejado de ser tan fuerte como al inicio) demasiado dilatado, a veces forzado y en otras ocasiones desproporcionado. Queriendo ser lo más fieles a Wojtyła traemos aquí sus mismas palabras sobre su obra al final de la misma: "Este trabajo ha intentado que emerja desde la experiencia de la acción aquello que muestra que el hombre es una persona, lo que desvela a esta persona; en cambio, no se ha pretendido construir una teoría de la persona como ente, es decir una concepción metafísica de la persona. Con todo, el hombre que se manifiesta como persona de la manera que hemos intentado mostrar en los análisis realizados hasta aquí parece que confirma suficientemente que su 'status' ontológico no sobrepasa las fronteras de la contingencia: esse contingens".

En síntesis, si bien se puede estudiar a Wojtyła desde diversas escuelas y

\footnotetext{
${ }^{6}$ Cf. J. M. Burgos, Para comprender a Karol Wojtyła, o.c., 76.

${ }^{7}$ En opinión de Guerra y a diferencia de Burgos, Marion se encuentra más en una perspectiva realista de la fenomenología con respecto a Wojtyła.

8 J. M. Burgos, Para comprender a Karol Wojtyła, o.c., 77 (vemos cómo Burgos intenta meter en este grupo a Buttiglione).

${ }^{9}$ K. WojtyŁa, Persona y acción, o.c., 425.
} 
perspectivas filosóficas, parece que es un error intentar encasillarlo en alguna escuela determinada, en varias o en crear nuevas escuelas. A nuestro juicio, Wojtyła no tiene intención de pertenecer tanto a una escuela (u otra) sino el descubrir la verdad del hombre. El poder iluminar su propia experiencia personal desde la inteligencia y desde ahí acercarse al hombre de todos los tiempos. Para esta gran empresa Wojtyła se vale de todo lo que le ayuda, se vale del tomismo como sustento ontológico y metafísico, se vale de la fenomenología para adentrarse en la interioridad y subjetividad del hombre, en todo lo que hay de irreductible en él y se vale del personalismo para remarcar la excelencia y preeminencia de la persona.

\section{EL MÉTODO FILOSÓFICO WOJTYLIANO}

\subsection{La centralidad de la experiencia}

Para comprender la centralidad de la experiencia en Wojtyła vale la pena hacer mención a dos momentos extra filosóficos decisivos que marcaron al autor y su concepción de la filosofía. El primero es de índole religiosoespiritual, tuvo lugar en el encuentro de Wojtyła con Jan Tyranowski y la espiritualidad carmelitana. Jan Tyranowski ${ }^{10}$ marcó profundamente al joven Wojtyła. Este era un sastre laico y catequista muy comprometido en la evangelización de los jóvenes. Tyranowski tenía, como más tarde reconoció Juan Pablo II, una experiencia de Dios muy personal y ello contribuyó a que

\footnotetext{
${ }^{10}$ Merece la pena recoger un texto de Juan Pablo II sobre este encuentro con Tyranowski en el $50^{\circ}$ aniversario de su ordenación sacerdotal: "En el ámbito de la parroquia había una persona que se distinguía sobre los demás: me refiero a Jan Tyranowski. Era empleado de profesión, aunque había decidido trabajar en la sastrería de su padre. Afirmaba que su trabajo de sastre le hacía más fácil la vida interior. Era un hombre de una espiritualidad particularmente profunda. Los padres Salesianos [...] le encargaron la tarea de establecer contactos con los jóvenes del círculo llamado Rosario vivo. Jan Tyranowski llevó a cabo esta tarea no ciñéndose únicamente al aspecto organizativo, sino preocupándose también de la formación espiritual de los jóvenes que entraban en contacto con él. Aprendí así los métodos elementales de autoformación, que se vieron después confirmados y desarrollados en el proceso educativo del seminario. Tyranowski, que se estaba formando en los escritos de San Juan de la Cruz y de Santa Teresa de Ávila, me introdujo en la lectura, extraordinaria para mi edad, de sus obras" (JuAn PABlo II, Don y misterio, B.A.C. Madrid 1996, 38).
} 
Wojtyła profundizara en su experiencia de Dios a través de la oración, de modo que esta experiencia diera sentido a cada aspecto de su vida. Fue por entonces cuando Wojtyła se adentró en las grandes obras teológicas de san Juan de la Cruz: Subida al monte Carmelo, Noche oscura del alma, Cántico espiritual, Llama de amor viva ${ }^{11}$.

Metodológicamente esta experiencia motivará a Wojtyła a desarrollar paulatinamente una vía filosófica que busque objetivar la experiencia subjetiva tanto en el orden sobrenatural como en el natural. En esta clave será decisivo para Wojtyła comprender no solo lo que sucede cuando acontece una experiencia sino contemplar y estudiar cómo el contenido de esa experiencia despliega una faceta de la verdad difícilmente perceptible desde otro punto de vista. De este modo, la experiencia se configura como el lugar donde acontecen los fenómenos y en el que ellos mismos anuncian su contenido cognoscitivo en el sujeto que los vive desde dentro.

Por otro lado, el acercamiento juvenil de Wojtyła al Teatro Rapsódico supone también una aportación importante a la conformación de su método filosófico y esto por varios motivos: primero, porque la experiencia teatral en sí misma introduce pedagógicamente a la persona dentro del universo de los signos y representaciones poéticas que nos aproximan a ciertos matices de la realidad humana que no son alcanzable siempre por el discurso puramente racional. Por otro lado, su maestro Mieczyslaw Klotarczyck ${ }^{12}$ indirectamente se inspira en una teoría del teatro ${ }^{13}$, que en parte bebe del pensamiento de Rudolf Otto, quien sostenía la necesidad de apreciar lo trascendente no solo a través de la moral o de la experiencia de lo bello y de lo sublime, sino a través de la experiencia de lo santo y de lo sagrado, categorías de valor que son específicas del fenómeno religioso ${ }^{14}$.

${ }^{11}$ Cf. G. Weigel, Biografía de Juan Pablo II, Testigo de esperanza, Plaza \& Janés, Barcelona 1999, 96-97.

${ }^{12}$ Fundador del Teatro Rapsódico "in cui il ruolo fondamentale era affidato alla parola bella che rivela la forza etica e morale dell'amore umano legato alla verità" (S. GRYGIEL, Dialogando con Giovanni Paolo II, Cantagalli, Siena 2013, 24).

${ }^{13}$ Cf. R. Buttiglione, Il pensiero dell'uomo che divenne Giovanni Paolo II, Mondadori, Milano 1998, 423.

${ }^{14}$ Cf. R. OtTo, Lo santo, in: Revista de Occidente, Madrid 1965. 
Klotarczyck recupera la importancia que posee el reconocer la especificidad de los datos experienciales en su propio ámbito sin confundirlos o mezclarlos con otros datos anexos o similares. Esta idea le impulsa a comprender el drama como la dimensión más importante de la vida, más aún, como el medio para transmitir la verdad acerca de la vida ${ }^{15}$. En el teatro rapsódico el drama no se presenta a través de un complejo escenario sino utilizando el poder de las palabras, "haciendo un teatro de la palabra viva" 16 donde el lenguaje entra en relación con la intimidad de la conciencia, en el diálogo desnudo que se establece entre quien habla y quien escucha.

De esta manera, el arte no proyecta las urgencias inmediatas sino la dimensión profunda de la existencia reconstruyendo las proporciones entre pensamiento y gesto a las cuales el hombre, al menos inconscientemente, a veces se extiende. La acción así evita afirmarse como pura manifestación extrínseca que se agota en la limitación empírica, más bien, la acción brota de la palabra interior donde la verdad del hombre se encuentra con la verdad del mundo.

En la misma línea R. Buttiglione afirma: "Para una hermenéutica de la existencia que capte a la vez el valor universal y la unicidad irrepetible del acontecimiento en el que se viene a manifestar, el lenguaje poético ofrece una ayuda fundamental"17. De esta actividad nos interesa resaltar el hecho de que por medio de su inmersión en la práctica poética y en el teatro comprendiera que el sentido más profundo de la existencia humana se descubre interiormente y desde él la acción adquiere pleno significado.

En consecuencia, la participación de Wojtyła en la espiritualidad carmelitana y en el mundo de la poesía a través del Teatro rapsódico son actividades que abren pedagógica e indirectamente a nuestro autor al difícil y polémico tema del punto de partida experiencial de la reflexión humana. Wojtyła mantiene una apertura que acepta cualquier dato sin ninguna restricción, sin anteponer un criterio previo que pase la experiencia por alto. En esta línea Wojtyła comenzará a distinguirse del planteamiento fundamental de la modernidad ilustrada y empirista, que coloca a la razón crítica como criterio

${ }^{15}$ Cf. G. Weigel, Testigo de Esperanza, Plaza \& Janés, Barcelona 1999, 65.

${ }^{16}$ Juan PaBlo II, Don y misterio, B.A.C. Madrid 1996, 24.

${ }^{17}$ R. Butiglione, Il pensiero dell'uomo che divenne Giovanni Paolo II, o.c., 311. 
exclusivo para el saber, restringiendo de modos diversos la amplitud de la experiencia. En contra, Wojtyła a través del crecimiento en la fe y a través del mundo del arte se prepara para la escucha de la voz misma del ser y se previene de todo aquello que no lleve las credenciales de lo inmediatamente dado en la experiencia.

\subsection{Diferencia entre la experiencia y el empirismo}

Adentrándonos ya en lo propiamente filosófico, digamos que el término experiencia ( $\varepsilon \mu \pi \varepsilon \imath \rho i ́ \alpha)$ significa para Aristóteles una forma de saber primario sobre lo particular, sus elementos son la sensación y la memoria que organiza las sensaciones. Es un saber mostrativo, no demostrativo. Por esto, las ciencias que parten de la experiencia y desde ella se elevan a lo universal son

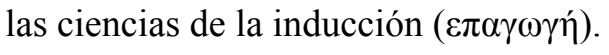

En el saber práctico la experiencia juega un papel que no se puede suprimir, por eso, Aristóteles dirá que "para saber lo que hay que hacer, hay que hacer lo que queremos saber" 18 . En el pensamiento kantiano, la experiencia se reduce a una rapsodia de percepciones sin unidad ni orden previos y a ella se sobreponen las categorías a priori del entendimiento. En este sentido, el conocimiento objetivo es el producto de una síntesis entre lo aportado fenoménicamente por la experiencia y lo puesto con necesidad a priori por el entendimiento, comportándose ambos elementos entre sí como lo material y lo formal, ambos claramente diferenciados y siendo excluyentes el uno con respecto al otro.

Aparte del proceder de lo simple a lo compuesto, otro rasgo de la experiencia en este sentido empirista es la pasividad con que se impone, desplazando toda participación activa del sujeto en ella. El entendimiento es visto como una tabla rasa, pizarra en la que no hay nada escrito, y los contenidos de experiencia se articulan por sí solos con arreglo a sus propias leyes asociativas de coexistencia, sucesión, etc., sin que de ellos se pueda extraer una configuración o significado unitario que pudiera ser objeto de experiencia. Es así como la experiencia en la corriente del empirismo se asemeja a una química mental.

\footnotetext{
${ }^{18}$ ARISTÓteles, Ética a Nicómaco, 1103, a. 32-33.
} 


\subsection{La experiencia moral}

La experiencia moral es una experiencia específica al lado de otras, tan es así que uno puede llegar a descubrir la moralidad de sus acciones a través de la experiencia. Cabe decir que el empirismo la obvia al trabajar con un modelo unívoco de experiencia. Sin embargo, no hay un concepto común y unívoco de experiencia que se pueda determinar desde fuera de las distintas variantes de experiencia y que se aplique a todas ellas. Más bien, como fácilmente se puede constatar, hay una experiencia del esfuerzo, una experiencia lúdica, una experiencia de la colaboración, estética, moral, religiosa... no uniformables según algo común. A este respecto Wojtyła afirma que la noción de experiencia no es estrictamente unívoca, por lo que cuenta con la posibilidad de elaborar una cierta concepción unitaria e integral de la experiencia, operativa también en el campo de la ética, lo que parece imposible en el interior de la posición radical empirista ${ }^{19}$.

En este sentido, la fenomenología ha hecho suyo el método de la reducción a lo esencial, desprendiéndose de todo aquello variable y accesorio a la esencia de que se trate. La experiencia en sentido moral es irreductible, ya que no se deja reducir a un plano no moral, por muy entrelazado que aparezca con ella. Los condicionantes psíquicos y sociales de la moralidad no son constitutivos suyos, sino que más bien se pueden entender como vías adecuadas o transitables de acceso a una experiencia moral determinada.

Lo específico de la experiencia moral es que paradójicamente resulta ser a la vez singular, propia del yo humano al que puede ser atribuida, y universal o específica, en cuanto que cualifica al yo como humano, sea uno u otro el autor. Es una experiencia que se cumple en primera persona, pero a la vez se refiere a lo que caracteriza específicamente al ser humano. Es a lo que apunta la expresión clásica actus humanus, como lo realizado por alguien en concreto y al mismo tiempo como provisto de una especificación o sentido universal.

Esta cierta paradoja de la experiencia moral se vuelve comprensible cuando se repara en que lo que se desvela en ella es el hombre como perso-

${ }^{19}$ Cf. K., WojtyŁa, "El problema de la experiencia en la ética", Mi visión del hombre, Palabra, Madrid 2005, 342s. 
$n a$, a la vez presente en todos los hombres y de un modo propio, en cada uno. Wojtyła lo expresa en los siguientes términos: "La especificidad de la moralidad solo puede aferrarse en el interior de la persona humana; en ningún otro lugar. No obstante, no es este interior lo que constituye exclusivamente el campo de nuestra experiencia. El perfil personal de la moralidad emerge en ella, en un cierto sentido, al mismo tiempo que el perfil social”20.

En la experiencia moral se conjugan la receptividad de lo acogido o de aquello de lo que se ha tenido experiencia y la actividad del sujeto que pasa por dicha experiencia. No se trata simplemente de que me suceda algo, sino de que haga propio de una u otra forma aquello que me sucede. Es la experiencia del yo actúo libremente, donde la libertad designa con toda propiedad la presencia de la persona que se distingue de los actos que hace suyos.

\subsection{La persona como fuente de validación} de la experiencia moral

Para Scheler, la persona es el agente común que unifica actos de esencia diversa y los convierte en efectivos; en este sentido, la persona no es un yo oculto o clandestino tras los actos, sino la fuente de todos y cada uno de ellos, para lo cual ha de estar provista de un dinamismo peculiar frente a lo que es un objeto intencional. La persona es el punto de convergencia de los actos, pero a la vez el quién activo al que se debe la realización de dichos actos.

A diferencia de Scheler, para Wojtyła el agente no es solo el foco del que irradian los actos dándoles concreción, sino que es la unidad óntica del suppositum en el que tienen su origen tanto las actuaciones conscientes como las activaciones motoras inconscientes; por ello, el yo-persona, que tiene por propios respectivamente ambos estratos de actividad, es uno y el mismo. Igualmente, es uno con el sujeto que se hace consciente de sí de modo pasivo cuando algo vivencial sucede en él. Además, para Wojtyła en el actuar es el yo quien gobierna su dinamismo, mientras que en la subjetividad de la vivencia de que algo sucede en mí el yo se encuentra llevado por su dinamización, sin que esto signifique

\footnotetext{
${ }^{20} \mathrm{~K}$. WojtyŁA, "El problema de la experiencia en la ética”, o.c., 341.
} 
que a posteriori no se los pueda unificar como un mismo yo y señalar sus límites, según el yo que tiene dicha acción como suya.

Veamos un texto de Wojtyła en el que se refiere a esta unidad del sujeto que actúa y que se vivencia pasivamente: "El hombre tiene la vivencia de sí como sujeto cuando sucede algo en él. En cambio, cuando él actúa tiene la vivencia de sí como agente [...]. A esas vivencias les corresponde una unidad estructural plena. La subjetividad se manifiesta estructuralmente ligada con el suceder-en, mientras que la operatividad está ligada estructuralmente con la actividad del hombre [...]. A pesar de una diferenciación y contraposición tan patente - en particular en el aspecto interno de la experiencia-, no se puede negar que quien actúa es el mismo en el que a la vez sucede esto o aquello. Es incuestionable la unidad e identidad del hombre sobre la base de la diferencia entre el actuar y el suceder-en"21.

Para Wojtyła se trata de una experiencia universal la de que cualquier hombre trascienda como persona tanto las activaciones vegetativas que ocurren en él como los actos en los que se revela conscientemente experimentándose como "yo".

En este sentido, la conciencia de la persona está en la base de todo comportamiento moral: "Toda la sensibilidad moral consiste en desvelar en los actos el momento personal como momento puramente humano que se abre paso y emerge a través de todas las tramas puramente cosificadas del contenido de nuestro obrar",22.

\subsection{El método filosófico de Karol Wojtyła}

El mismo Wojtyła expone su propio método en Persona y acción antes de adentrarse en los temas que más le interesan. Lo hace ofreciendo una ayuda al lector para que tenga las claves adecuadas y pueda comprender la originalidad de su pensamiento. Es un método que en ciernes se encontraba ya en Amor y responsabilidad, pero que ahora Wojtyła ya ha madurado y lo expone sistemáticamente.

\footnotetext{
${ }^{21}$ K. WoJTYŁa, Persona y acción, o.c., 127.

${ }^{22}$ K. WojtyŁA, "El hombre y la responsabilidad", El hombre y su destino, Palabra, Madrid 2005, 291.
} 
Wojtyła afirma que el estudio ofrecido en Persona y acción nace de la "necesidad de objetivar la totalidad de ese gran proceso cognoscitivo que se puede definir básicamente como experiencia del hombre",23. La experiencia, la podemos definir, grosso modo, como el proceso primario y vivencial por el que la persona se relaciona con el mundo, mientras que la comprensión viene a ser la consolidación cognoscitiva de dicha experiencia, es decir, la elevación a conocimiento expreso de la experiencia que toda persona acumula. Wojtyła entiende la experiencia como una carga cognoscitiva que posee simultáneamente dos dimensiones, una que es objetiva y externa y otra, en cambio, que es subjetiva y autorreferencial: "La experiencia de cualquier cosa que se encuentre fuera del hombre siempre conlleva una cierta experiencia del propio hombre. Pues el hombre nunca experimenta nada externo a él sin que, de alguna manera, se experimente simultáneamente a sí mismo" ${ }^{24}$.

La experiencia se refiere ante todo al hecho de que el hombre se dirige cognoscitivamente hacia sí mismo, estableciendo de este modo un contacto cognoscitivo consigo. Se pueden tener momentos de mayor o menor nitidez, pero todos estos momentos constituyen el conjunto particular de experiencias de ese hombre que soy yo, el que actúa. La experiencia, por tanto, está constituida de muchas experiencias resultando ser esta como la suma de todas ellas, o mejor dicho el resultado de las mismas ${ }^{25}$.

Para Wojtyła, un planteamiento puramente fenoménico no admitiría la existencia de esta unidad formada a partir de muchas experiencias, ya que este planteamiento ve en cada experiencia individual únicamente un conjunto de impresiones o de emociones que posteriormente son ordenadas por el entendimiento. Aunque es cierto que cada experiencia es única e irrepetible, "existe algo que podemos llamar experiencia del hombre" ${ }^{26}$, la cual se fundamenta en la continuidad de los datos empíricos. "El objeto de tal experiencia no es solo un fenómeno sensible transitorio, sino también el propio hombre que se revela en todas las experiencias y que, a la vez, está en cada una

\footnotetext{
${ }^{23}$ K. WojtyŁa, Persona y acción, o.c., 31.

${ }^{24}$ Ibid.

${ }^{25}$ Cf. ibid., 32.

${ }^{26}$ Ibid.
} 
de ellas" ${ }^{, 27}$. Asimismo, la experiencia del hombre, el hombre que es cada uno, perdura en tanto que se mantiene el contacto cognitivo directo del que yo soy, por un lado, sujeto y, por otro, objeto.

La diferencia entre experiencia y comprensión estriba en que "la comprensión de sí mismo se compone de muchas comprensiones, de manera parecida a como la experiencia se compone de muchas experiencias. Parece que cada experiencia sea también una cierta comprensión"28. En este sentido, queda patente la inseparable conexión entre experiencia y comprensión, al mismo tiempo que ambas se enriquecen y se constituyen en el cúmulo de muchas experiencias y comprensiones obtenidas a lo largo de la existencia.

\section{a) La experiencia como base del conocimiento sobre el hombre}

Siguiendo con el análisis de la experiencia, Wojtyła va dando pequeños pasos progresivos para ir explicando su método, es consciente de la dificultad que entraña su exposición a nivel pedagógico y por ello irá repitiendo las ideas nucleares a la vez que enriquece estas con nuevas aportaciones. Ahora, explicando que todo lo anterior se refería a un "único hombre, a mí mismo", dirá que aparte de uno mismo, también los otros hombres son objeto de la experiencia, ya que esta "se compone de la experiencia de sí mismo y de la experiencia de todos los demás hombres que se encuentran en situación de objetos de experiencia respecto al sujeto [...], en directa relación cognoscitiva con él”29.

En la misma línea y aclarando las cosas, la experiencia de un hombre en particular no puede alcanzar la experiencia de todos los hombres, es algo imposible, porque siempre se limita a un cierto número de hombres, que puede ser mayor o menor dependiendo de cada individuo. Por ello, el aspecto cuantitativo juega un papel importante en la experiencia del hombre, ya que obviamente, cuanto mayor sea el número de hombres que integran la experiencia de una persona, mayor y más rica es dicha experiencia.

\footnotetext{
${ }^{27}$ Ibid.

${ }^{28}$ Ibid.

${ }^{29}$ K. WojtyŁa, Persona y acción, o.c., 33.
} 


\section{b) El "yo" y el "hombre" en el ámbito de la experiencia}

Para Wojtyła hay una distinción entre ambos tipos de experiencia, por ejemplo, la que el hombre tiene de sí mismo — que supone la captación directa de la subjetividad - y la experiencia que el hombre tiene de los demás hombres, teniendo esta una dimensión más objetiva y externa, sin dejar por ello de ser experiencia. "Se trata de dos experiencias distintas y diferentes, pero no irreducibles entre sí" ${ }^{30}$. Entre ambas, existen continuidades que permiten que se integren configurando una estructura compleja pero unitaria al mismo tiempo.

Algo fundamental de ambas experiencias, es el hecho de que se dan simultáneamente: "Yo no soy para mí mismo tan solo una 'interioridad', sino también una 'exterioridad', ya que soy objeto en ambas experiencias, la exterior y la interior. Y también cualquier otro hombre distinto de mí, aunque para mí sea tan solo objeto de experiencia desde el exterior, en el conjunto de mi conocimiento no se presenta como pura 'exterioridad', sino que tiene también su propia interioridad, que conozco a pesar de que no sea para mí objeto de experiencia directa: conozco la interioridad de los hombres en general y, en ocasiones, conozco mucho de algunos hombres en particular"

Para Wojtyła la estructura fundamental de la experiencia está formada por "la experiencia del yo" y la "experiencia del hombre", que se interconectan entre sí de diversos modos. Aquí se podría aludir a una dificultad, que es el lugar que ocupa la experiencia durante el sueño, o en los tipos específicos de experiencia: la moral, la estética, etc. Sin embargo, Wojtyła no se detiene demasiado en estos aspectos complejos y difíciles de articular. A él le basta con fijar su concepto central de experiencia, que como hemos visto, consiste en la integración de subjetividad y objetividad. Todo lo demás el mismo hombre logra integrarlo y unificarlo sin demasiadas dificultades.

\footnotetext{
${ }^{30} \mathrm{~K}$. WoJTYŁA, Persona y acción, o.c., 34

${ }^{31}$ K. WojtyŁa, Persona y acción, o.c., 37.
} 


\subsection{El conocimiento de la persona se fundamenta en la experiencia del hombre}

a) Diferencia entre el punto de vista empirista y el punto de vista fenomenológico

La experiencia en Wojtyła, indicábamos antes, no se puede entender de manera puramente fenoménica, como lo hace el pensamiento empirista. No es posible admitir que los datos de la experiencia directa sean únicamente un conjunto poco definido de cualidades sensibles que están en el hombre (o que son del mismo hombre) "y que, en cambio, no lo sea el hombre mismo; que no lo sea el hombre y su actuar consciente, o sea, la acción" ${ }^{, 32}$.

Desde un punto de vista fenomenológico, la experiencia es la fuente y la base de cualquier conocimiento sobre el objeto, lo cual no implica que exista un solo tipo de experiencia, y que esta experiencia sea la percepción que se da a través de los sentidos externos o internos. Para los fenomenólogos, la "experiencia directa" es cualquier acto de conocimiento, en el que el objeto se da a sí mismo, de manera originaria, o en palabras de Husserl "corpóreamente autopresente" (leibhaftselbstgegeben). Hay muchos tipos de experiencia en que los datos son objetos individuales; por ejemplo, la experiencia de los actos psíquicos de otros individuos, también la experiencia estética, la experiencia de los objetos ideales lógico-matemáticos, etc.

\section{b) El punto de partida es el hecho "el hombre actúa", que es un dato de la experiencia fenomenológica}

Aclarado el punto anterior, ahora Wojtyła se apresta a dejar bien claro que el punto de partida es siempre "el hombre actúa", a quien le son atribuidos, o mejor aún, a quien le corresponden el conjunto de datos dinámicos basados en un cierto tipo de hechos. Por ello, si tenemos en cuenta la experiencia "el hombre actúa" de todos los hombres que podamos, obtendremos consecuentemente un inabarcable número de hechos y, por ende, una "enorme riqueza experimental" ${ }^{, 3}$.

\footnotetext{
${ }^{32}$ K. WojtyŁa, Persona y acción, o.c., 39.

${ }^{33}$ K. WojtyŁa, Persona y acción, o.c., 40.
} 
Una gran aportación que hace Wojtyła a la teoría del conocimiento, es la de establecer la conexión entre experiencia y la inmediatez en el propio conocimiento, esto es, la relación directa del cognoscente con el objeto. Para él resulta difícil admitir que tan solo el acto sensible aprehenda de modo directo los objetos o los hechos. Wojtyła sostiene que el acto intelectual al menos colabora en la autoaprehensión directa del sujeto. Dicha inmediatez "como rasgo experimental del conocimiento, no anula la diferencia de contenido entre el acto intelectual y el acto puramente sensible, ni tampoco su diversidad de origen" ${ }^{34}$.

La tesis wojtyliana al respecto, es dejar claro que no se puede aceptar la idea de que la experiencia se limite a la pura "superficie", es decir, al conjunto de rasgos sensibles que son en cada ocasión únicos e irrepetibles y que presentados al entendimiento este haría de ellos su propio objeto, al que denominaría "acción". Sino que más bien, hay que afirmar que el entendimiento interviene ya en la propia experiencia, gracias a la cual establece una relación con el objeto.

\section{c) La acción como momento privilegiado de profundización en la persona}

La propuesta wojtyliana es totalmente contraria al fenomenismo siendo más cercana a la propia de la fenomenología, en la medida en que acentúa ante todo la unidad del acto de conocimiento humano. Esta es la razón de su tesis: "sostenemos que la acción es un momento particular en la aprehensión -o sea, en la experiencia - de la persona" ${ }^{35}$. A lo que se refiere es a una visión intelectual, que se fundamenta sobre el hecho "el hombre actúa" en todas sus innumerables modalidades. De aquí la gran novedad del enfoque del autor al afirmar que no se trata del estudio de la acción basado en la persona, sino que es "un estudio de la acción que presupone a la persona, o sea, un estudio de la persona a través de la acción" $"$. La acción se convierte, de este modo, en el momento privilegiado donde se revela la persona, y de esta forma, nos permite analizar adecuadamente su esencia y comprenderla de la

\footnotetext{
${ }^{34}$ Ibid.

${ }^{35}$ K. WojtyŁa, Persona y acción, o.c., 41.

${ }^{36} \mathrm{~K}$. WojtYŁA, Persona y acción, o.c., 42. Este planteamiento coincide con el que expresó M. BLONDEL en su obra clásica L'action, Paris 1937.
} 
forma más completa posible. En suma, que el hombre es persona se descubre porque realiza acciones y tiene experiencia de ellas.

\section{d) La moralidad, cualidad propia de las acciones humanas}

A la luz de lo anterior podemos comprender mejor que las acciones poseen valor moral, pueden ser moralmente buenas o moralmente malas. La moralidad no es para la acción algo accidental, un mero accidente ontológico, sino que constituye su propiedad intrínseca. Aquí radica la diferencia entre las acciones de la persona y la de otros agentes distintos a ella. Por lo que "solamente tienen significado moral las actividades cuyo agente es una persona" ${ }^{37}$.

Se establece así una estrecha relación entre moral (ética) y acción. Ciertamente no es el objeto del autor estudiar los valores morales en sí mismos, sino que le importa ante todo el hecho mismo de su constitución en acciones, su dinámico fieri. Es aquí donde la persona se revela de manera más profunda. Igualmente, desde este aspecto, dinámico-existencial, de la moralidad, podemos conocer mejor al hombre en cuanto persona.

Más aún, la moralidad en el estudio de la acción tiene una relevancia nuclear para Wojtyła, ya que los valores morales, bien y mal, no solo determinan la propiedad interior de los actos humanos, sino que revierten sobre el hombre haciéndole llegar a ser él mismo bueno o malo en cuanto persona $a$ través de sus actos moralmente buenos o moralmente malos ${ }^{38}$. Este punto es de gran importancia para comprender que la acción tiene un carácter perfectivo y a través de ella la persona puede llegar a ser mejor o, por el contrario, puede degradarse hasta abismos insospechados.

Persona y acción se caracteriza por el hecho de que no da por supuesta a la persona al igual que tampoco la implica, sino que, al contrario: "pretende explicar esa realidad que es la persona con tanto detalle como sea posible",39. En este sentido, la fuente desde la cual se extrae el conocimiento de la persona es doble, por un lado, a través de la acción y por otro, a través de la moralidad en su aspecto dinámico-existencial.

\footnotetext{
${ }^{37}$ K. WojtyŁa, Persona y acción, o.c., 43.

${ }^{38}$ Cf. K. WojtyŁa, Persona y acción, o.c., 44.

${ }^{39}$ K. WojtyŁa, Persona y acción, o.c., 45.
} 


\subsection{Etapas de la comprensión y líneas de interpretación}

\section{a) La inducción como captación de la unidad de significado}

Entre la gran multiplicidad de acciones que se dan en el hombre, las más importantes son aquellas en las que "el hombre actúa", ya que en ellas se realiza el descubrimiento específico de la persona a través de la acción. Ahora bien, es tarea de la inducción el captar a partir de la gran multiplicidad y complejidad de hechos su "sustancial identidad cualitativa" 40 .

La experiencia nos muestra múltiples hechos en los que se dan conjuntamente la persona y la acción; es gracias a la inducción como llegamos a la “constatación de que en cada uno de los casos 'el hombre actúa' se encuentra una revelación 'persona-acción' del 'mismo tipo', que es el mismo tipo de persona que se manifiesta a través de la acción. Identidad cualitativa que equivale a una identidad de significado" ${ }^{\prime 4}$. Alcanzar la unidad en la multiplicidad de experiencias es obra de la inducción, ya que la experiencia en sí misma nos deja una diversidad de casos, mientras que es el entendimiento el que capta por medio de la inducción la unidad de significado en todos ellos. Mediante la inducción, de tipo aristotélico ${ }^{42}$, el hombre consolida esas experiencias en las que busca lograr una unidad de significado; encuadra los conocimientos en su especie, pero teniendo cuidado de no perder la dimensión subjetiva del conocimiento ni la riqueza de los detalles.

\section{b) La reducción como "exploración" "43 de la experiencia}

En estrecha relación con el concepto de inducción, Wojtyła estudiará y se valdrá de otra herramienta metodológica: la reducción. Esta no es una reducción entendida como disminución o limitación de la riqueza del objeto experimentado, sino que más bien lo que hace es extraer las consecuencias de lo

\footnotetext{
${ }^{40}$ K. WojtyŁA, Persona y acción, o.c., 47.

${ }^{41}$ Ibid.

${ }^{42}$ Distanciándose de como la entiende, por ejemplo, J. S. MiLL, para quien la inducción es una forma metodológica de la ciencia experiencia experimental a través de los célebres cánones de las semejanzas, diferencias y variaciones concomitantes (Cf. Ibid).

${ }^{43}$ El término polaco es "eksploatacja", cuyo significado literal es el de "explotación", en el sentido de extraer todas las riquezas de algo.
} 
dado en la experiencia: "la explotación de la experiencia debe ser un proceso cognitivo, en el que se realiza de manera estable y homogénea el desarrollo de la visión originaria de la persona en la acción y a través de la acción [...]. Reducere equivale a 'extraer' desde los argumentos o principios adecuados o, de otro modo, explicar clarificar, interpretar" ${ }^{\text {,4 }}$.

Cuando se explica se avanza tras el objeto que nos es dado en la experiencia, y precisamente tal y como nos es dado, con toda su riqueza, variedad y complejidad de la experiencia abriéndose ante nosotros. Si la inducción lo que hace es acopiar los materiales y captar su sentido, en cambio la reducción intenta explicar, aclarar e interpretar tanto el eidos como su relación con las experiencias individuales. La misión de la reducción es así la intelección más perfecta posible de la experiencia; su misión consiste en expresar y explicitar esa inteligibilidad, llegando a lo más hondo posible, a la esencia del hombre.

\section{c) El proceso de comprensión: inducción y reducción}

La relación de estos elementos puede resultar a primera vista paradójica, ya que se conectan mediante un proceso simultáneo de inmanencia y trascendencia. La reducción, no solo la inducción, es inmanente respecto a la experiencia, sin dejar de ser trascendente respecto a ella, aunque de forma distinta a como lo es la inducción. La comprensión es, al mismo tiempo, inmanente y trascendente respecto a la experiencia del hombre: por ello, en esta se encuentra todo, ya que no es un hecho sensible y superficial, sino que la experiencia nos da la realidad en toda su profundidad. Aunque, en cierta manera, y de modo paradójico, no queda más remedio que "salir" de la experiencia para interpretarla o aclararla. No obstante, inmediatamente hay que señalar que, aunque se "sale" de la experiencia, es solo para analizarla y para retornar a la misma experiencia, para conocerla mejor y con más profundidad. Esto es lo que hace ver cómo la inducción al igual que la reducción son, al mismo tiempo, inmanentes y trascendentes a la vivencia experimental.

\footnotetext{
${ }^{44}$ Ibid., 49s.
} 


\section{CONCLUSIÓN}

Este estudio nos ha permitido ver la novedad del método filosófico de Karol Wojtyła para el estudio antropológico de la persona humana. Tras la exposición del mismo Wojtyła estudiará dos grandes apartados: la trascendencia de la persona en la acción y la integración de la misma en la acción. Es un método que le llevará a captar lo esencialmente humano, lo más profundo del ser personal, su misma subjetividad sin dejar de lado la dimensión objetiva y metafísica de la misma.

Digamos que este método no habría sido posible sin la importancia que Wojtyła da a la experiencia como fuente de conocimiento, una experiencia que es anterior y de la cual se sirvió como joven sacerdote para adentrarse en el conocimiento del ser humano y de todo aquello que es propiamente humano: el amor, la conciencia, las relaciones interpersonales, el sistema prójimo y comunidad, etc. Por todo ello, concluimos afirmando la actualidad y vigencia del método filosófico wojtyliano para conocer al hombre de hoy, a cada hombre, al hombre de todos los tiempos. 